ESJ Social Sciences

\title{
Migración Circular, Gestión y Rentabilidad de la Fuerza de Trabajo: El Caso de la Comunidad Agrícola de José Narciso Rovirosa, Quintana Roo
}

\author{
Eliana Cárdenas Méndez \\ Miembro del Sistema Nacional de Investigadores, Nivel 1 \\ Doctora en Antropología, Profesora-Investigadora, de la División de \\ Humanidades y Lenguas, Universidad de Quintana Roo, Mexico \\ Zuemy M. Cahuich Cahuich \\ Maestrante del Programa en Antropología Aplicada de la Universidad de \\ Quintana Roo, Universidad de Quintana Roo, Mexico
}

Doi:10.19044/esj.2021.v17n27p99

Submitted: 15 June 2021

Accepted: 24 July 2021

Published: 31 August 2021
Copyright 2021 Author(s)

Under Creative Commons BY-NC-ND

4.0 OPEN ACCESS

Cite As:

Méndez E.C. \& Cahuich Z.M.C. (2021). Migración Circular, Gestión y Rentabilidad de la Fuerza de Trabajo: El Caso de la Comunidad Agrícola de José Narciso Rovirosa, Quintana Roo. European Scientific Journal, ESJ, 17 (27), 99.

https://doi.org/10.19044/esj.2021.v17n27p99

\section{Resumen}

El propósito de este artículo es presentar las dinámicas de las nuevas formas de gestión y de apropiación de la fuerza de trabajo en el capitalismo global, tomando en cuenta la migración circular de los jornaleros agrícolas temporales de la comunidad de José Narciso Rovirosa, del Estado de Quintana Roo, que migran cíclicamente, mediante el programa de empleo temporal PTAT, a trabajar en las granjas de Canadá. Se parte de una presentación general sobre el concepto de migración circular entendida, en este trabajo, como el patrón de desplazamiento característico del capitalismo global para la maximización y rentabilidad de la fuerza de trabajo proveniente de países en desarrollo. Se afirma que los migrantes circulares encuentran en las comunidades de origen entramados económicos, sociales y políticos, que no permiten que las remesas obtenidas mediante condiciones de sobreexplotación en las granjas canadienses, se conviertan en fuente de desarrollo para la comunidad; pone en discusión la justificación para la gestión de la migración como factor de desarrollo en las comunidades de origen, se reafirma en cambio 
la migración como dinámica causal acumulativa que obliga a los trabajadores a buscar en la migración el único horizonte de sobrevivencia.

Palabras clave: Migración circular, trabajadores agrícolas temporales, desarrollo local, emprendimien

\title{
Circular Migration, Management and Profitability of the Labor Force: The Case of the Agricultural Community of José Narciso Rovirosa, Quintana Roo
}

\author{
Eliana Cárdenas Méndez \\ Member of the National System of Researchers, Level 1 \\ Doctor in Anthropology, Professor-Researcher, Humanities and Languages \\ Division, University of Quintana Roo, Mexico \\ Zuemy M. Cahuich Cahuich \\ Master of the Applied Anthropology Program at the University of Quintana \\ Roo. University of Quintana Roo, Mexico
}

\begin{abstract}
This paper focuses on presenting the dynamics of the new forms of management and appropriation of labour power in global capitalism. It takes into account the circular migration of temporary agricultural labourers from the community of José Narciso Rovirosa, in the state of Quintana Roo, who migrate cyclically, through the temporary employment programme PTAT to work on farms in Canada. The paper begins with a general presentation of the concept of circular migration. This study is considered as the pattern of displacement characteristic of global capitalism for the maximization and profitability of the labour force from developing countries. It is affirmed that circular migrants find in their communities of origin economic, social, and political frameworks. These frameworks do not allow remittances obtained through conditions of overexploitation in Canadian farms to become a source of development for the community. It questions the justification for the management of migration as a factor of development in the communities of origin. It also reaffirms migration as an accumulative causal dynamic that forces workers to seek migration as the only horizon of survival.
\end{abstract}

Keywords: Circular migration, seasonal agricultural workers, local development, entrepreneurship 


\section{Introduction}

El anuncio de la cuarentena decretada en marzo de 2020, por las autoridades sanitarias en México y en Canadá debido a la pandemia ocasionada por el COVID-19, interrumpió la agenda de trabajo que se tenía prevista con los migrantes agrícolas de la comunidad de José Narciso Rovirosa que estaban próximos a regresar de Canadá. En estas circunstancias no se tuvo otro recurso que utilizar los medios digitales como los teléfonos celulares y la aplicación de WhatsApp para conocer las condiciones laborales de los trabajadores que se habían visto obligados a permanecer en las farmas en razón de la pandemia y de los apremios de los empleadores debido a los riesgos que corría la producción al no tener trabajadores de relevo, ocasionado por el cerco sanitario decretado en ambos países y el cierre de fronteras.

No fue sino hasta los meses de noviembre y diciembre de ese mismo año que se pudo reanudar el trabajo de campo in situ y las entrevistas cara a cara. Quizá de las más memorables por su intensidad fue la que se realizó en la amplia terraza con piso de loza y techo de lámina, propiedad de uno de los trabajadores de la comunidad que más estancias ha realizado en Canadá, un hombre de edad incalculable, con el rostro curtido por el sol, de manos fuertes y rudas, amasadas en el trabajo del campo; muy alto, una característica de los colonos típicos del norte avecindados en la zona sur del estado de Quintana Roo, que contrasta con los lugareños mayas.

Arribamos con la heladez $z^{1}$ de una mañana de diciembre, en plena alerta sanitaria por el COVID-19. Caminamos por las calles de roca calcárea de color blanco que los mayas de la península de Yucatán denominan saskab, escrutadas con sorpresa por los campesinos debido a nuestros cubre-bocas y pantallas sanitarias, pues allí la vida transcurría normal, alejada de la parafernalia de los medios de comunicación que alertaban sobre "quedarse en casa", "sana distancia", "uso de desinfectantes" y "tapabocas obligatorio"Don Jorge Gómez nos dio la bienvenida en su casa en medio del canto de los gallos, cacaraqueo de gallina, ladridos de perros y el coro ensordecedor, áspero y ronco de las chachalacas; en breve, puntuales a la cita, fueron llegando cerca de 20 trabajadores de la localidad que trabajan en los campos de Alberta, Quebec, Otawa, y Ontario.

Hacía una semana habían llegado a la comunidad después de diferentes estancias laborales en las farmas de Canadá; casi todos vestían pantalón de mezclilla y zapatos de marca, iban ataviados con playeras y gorras con distintivos alusivos a Canadá, las más notorias eran la flor de maple, el símbolo nacional, impreso en colores dorado o rojo y la bandera canadiense.

El hermetismo inicial cedió cuando aclaramos que no teníamos ninguna relación con la Secretaría de Trabajo y Previsión Social (STPS) ni

${ }^{1}$ Término local para designar el intenso frío húmedo de la península de Yucatán que llega con los vientos del norte en los meses de noviembre a febrero. 
con el Programa de Trabajadores Agrícolas Temporales (PTAT); que teníamos un propósito académico y nos interesaba conocer cuáles eran las circunstancias por las que migraban y conocer sobre las condiciones laborales en las farmas canadienses. La conversación fluyó cuando entró a la reunión un trabajador en muletas, por una lesión en el tobillo; la hinchazón y el hematoma eran notorias. ¿Qué le pasó? Indagamos:

Un accidente por descuido, contestó, "estaba lavando tractores y me enredé con una manguera, que estaba ahí, en el hueco donde echan mecánica, me confié y mi pie resbaló en el escalón, y se me fue mi tobillo; llevo varias temporadas y mi patrón respondió y me llevaron al quiropráctico, me tomaron radiografía, el patrón tiene seguro y lo cubre a uno, pero el seguro lo paga uno, te lo descuentan, si hay accidente de trabajo es $100 \%$ si es enfermedad $90 \%$. Estuve una semana esperando mi fecha de regreso, me llevaron al aeropuerto; me quedé solo y ahí tomé el avión a México, después esperé el avión a Cancún y de ahí tomé rápido el camión a Chetumal, y luego en taxi a Rovirosa, después de 16 horas de viaje llegué en la madrugada aquí a la comunidad. No me quise quedar en ninguna parte, lo único que quería era llegar a mi casa. Había pasado una dura y larga temporada a raíz del COVID-19.

Esta respuesta abrió paso a un torrente de relatos sobre las experiencias de la migración circular y las condiciones laborales de los trabajadores agrícolas temporales en Canadá, que sirven de soporte y justificación de esta investigación:

*-Uno tiene que aguantar porque, aunque hayas invertido en los papeles, pasaporte, trámites, en el boleto de avión, comida, te pueden sacar por cualquier cosa: si estás gordo o chiquitito o chaparrito, te dejan solo hasta que pagues tus deudas. Después a la jchingada! Los patrones son racistas, en Canadá hay racismo, vas por la calle y te dicen mauss, -ratón-los canadienses están celosos porque dicen que nosotros les quitamos el trabajo, pero si usted va al campo, es raro que usted vea un canadiense trabajando. Así es allá, si te quieres quedar tienes que demostrar, si estás chaparrito y vieron que trabajabas, que sacabas el trabajo, que dejaban el alma sacando el trabajo, entonces el patrón puede cambiar de opinión, la mayoría de las veces sucede, ellos saben que los mexicanos dejan el alma, pero sacan el trabajo.

*-Las diferentes granjas tienen sus exigencias, en las farmas de chiles, es un trabajo delicado y si no lo sabes hacer bien o no rindes te tratan muy mal, te exigen muchísimo, si no sabes o te equivocas te tratan súper mal.

*-La compañía no nos da ningún beneficio, el punto es sacarte el máximo, sino, pues te devuelven, te pueden recolocar, pero en todas partes es lo mismo, para ellos como empleadores, están comunicados y te hacen un expediente, cada empleador te califica, si has tenido problemas has sido borracho, si no limpias, si no rindes mucho, si te has nockeado al capataz, te califican y dependiendo de eso te vuelven a recontratar, sino te jodes. *-En cambio, ellos pueden incumplir, cuando llegas te dan las peores condiciones; es la antigüedad y el trabajo con un mismo patrón el que te permite tener mejores condiciones, tener un cuarto para ti solo, por ejemplo. 
*-Las condiciones son tan duras algunas veces que los mismos canadienses han llegado a reclamar. Una vez un canadiense, vecino de la farma, vio las condiciones en las que trabajábamos, sin seguridad, sin protección mínima, sin arnés a 8 metros de altura y le dijo que, si no nos protegían, iba a hablar y a acusarlos. Es que si te llegas a caer, te guardan y te mandan de pingüinito, y no te sirve de nada el pinche peso que te puedan dar, pero no puedes decir que no, al patrón le importas si haces de todo, limpias, si recoges, si manejas el tracktor, si barres, si eres operador, si la haces de albañil, de carpintero, mecánico, si estás a la orden para beneficiar la producción; cuando tienes un accidente haciendo cosas para las que no te han contratado puedes pelear te puedes defender, por ejemplo, si te contratan como agricultor, pero te mandan de carpintero o de albañil tú puedes reclamar; así mismo, a veces el patrón te manda a manejar tractor, pero si no sabes o no rindes te empieza a gritar y al maltratar puedes decirle que en tu contrato no dice que tengas que hacer esos trabajos, pero entonces ya sabes, te mandan derechito a México.

*-El patrón te dice: si quieren cobrarme tipo horas extras, entonces sólo les doy sus 8 horas, porque si les doy doce horas te las pago al mismo precio que las 8 del contrato, si quieres más dinero, si quieren un pago por horas extras, entonces hago otra casa y meto más gente y los perjudicados van a ser ustedes, porque yo les pago a todos por hora, pero al mismo precio; yo salgo ganando, tengo más brazos y no tengo que invertir más.

\section{Descripción metodológica}

El presente trabajo es resultado de una investigación etnográfica realizada en la comunidad de José Narciso Rovirosa, Quintana Roo, entre el 2018-2020. Tres preguntas principales orientan la investigación ¿Qué condiciones imperan en la comunidad que impulsan a campesinos ejidatarios a migrar a Canadá a trabajar como jornaleros agrícolas? ¿Cuáles son los mecanismos de contratación y las condiciones laborales en las farmas canadienses? ¿Cuáles son los significados que atribuyen los trabajadores agrícolas a la migración circular México-Canadá-México?

El objetivo general de este artículo es presentar las dinámicas de las nuevas formas de gestión y de apropiación de la fuerza de trabajo en el capitalismo global, tomando en cuenta la migración circular de los jornaleros agrícolas temporales de la comunidad de José Narciso Rovirosa. Adicionalmente la investigación persigue tres objetivos específicos: 1. Identificar las causas de la migración en esta comunidad, 2. Poner en discusión las ventajas de la migración circular, indicadas en el Programa de Trabajadores Agrícolas Temporales (PTAT) con las experiencias de los trabajadores de Rovirosa que migran a trabajar a las farmas de Canadá. 3. Identificar los significados que atribuyen los migrantes a la experiencia de la migración circular.

Se emplearon herramientas metodológicas propias de la investigación cualitativa: la observación participante, entrevistas y técnica de grupos focales. Se realizaron entrevistas abiertas y a profundidad a los seis 
funcionarios de base, encargados de la operación del Programa de Trabajadores Agrícolas Temporales (PTAT) en la Secretaría de Trabajo en Chetumal. El énfasis estuvo radicado en conocer el Programa de Trabajadores Agrícolas Temporales (PTAT) y la implementación del mismo en el estado de Quintana Roo.

Este ejercicio in situ, en la Secretaría de Trabajo, permitió, de forma complementaria, tener acceso al complejo proceso burocrático para la obtención de un visado temporal para trabajar en las farmas en Canadá; reconocer paralelamente, formas jurídicas que llevan implícita una concepción del trabajador migrante, en tanto cuerpo apto para el trabajo, e insumo del proceso productivo.

También se utilizaron herramientas propias de la etnografía digital, tomando en cuenta que lo digital se ha convertido en el locus inapelable que permite tener acceso a grupos poblacionales de diversos tipos, pero especialmente para aquéllos que están en movimiento. El uso de las tecnologías digitales como WhatsApp, Facebook y YouTube son herramientas que hacen parte de la cotidianidad de las personas y son imprescindibles para los migrantes con el propósito fundamental de mantenerse en constante comunicación con sus familias y su localidad de origen a través del intercambio de mensajes electrónicos. Mediante estas técnicas obtuvimos acceso a toda suerte de vicisitudes relacionado con el periplo migratorio de los migrantes a Canadá y su percepción y significados sobre este proceso dinámico circular que implica la vida en dos espacios sociales.

Finalmente, en la Comunidad de José Narciso Rovirosa, siguiendo la técnica del Grupo focal, se realizaron entrevistas a 10 migrantes beneficiados con visa temporal, que estaban próximos a realizar una estancia laboral en Canadá. Así mismo, se realizaron entrevistas a un colectivo de 20 trabajadores veteranos que llevan varios años realizando estancias en las farmas y que habiendo finalizado el periplo circular, estaban de retorno en la entidad.

\section{José Narciso Rovirosa, una comunidad de migrantes}

Después de varios mapeos y consultas estadísticas, se seleccionó la comunidad de José Narciso Rovirosa para esta investigación, por dos razones principales: 1. Por ser la entidad quintanarroense que más trabajadores agrícolas ha tributado al Programa de Trabajadores Agrícolas Temporales (PTAT) a lo largo de 21 años, y 2. Por el fuerte dinamismo migratorio circular México-Canadá-México; ambas consideraciones nos permiten comprender la dinámica de la migración circular México-Canadá-México, el impacto del programa en la comunidad y los significados que los trabajadores atribuyen a esa "vida de tiempo compartido" en dos espacios sociales.

Llegamos por primera vez a Rovirosa, la penúltima comunidad de la zona limítrofe México Belice, después de un caluroso y bochornoso viaje de 
90 minutos por una estrecha carretera, recta, sin horizonte, atravesando un monótono paisaje de color verde con sembradíos de caña de azúcar a lado y lado, interrumpido por pequeños cerros y el asomo perpendicular de algunas carreteras de saskab que ocasionalmente indicaban la entrada a una comunidad. Así, sin señal de internet ni GPS, avisadas por un letrero desvencijado con letras blancas sobre un fondo verde, llegamos a nuestro destino.

José Narciso Rovirosa es una localidad perteneciente al municipio de Othón P. Blanco en el estado de Quintana Roo, se encuentra localizada a 79 $\mathrm{Km}$ de Chetumal la cabecera municipal, a una hora y quince minutos aproximadamente, sobre la ruta 186 de la carretera federal a Escárcega, con dirección a La Unión y atravesando Álvaro Obregón (MAPS, 2020).

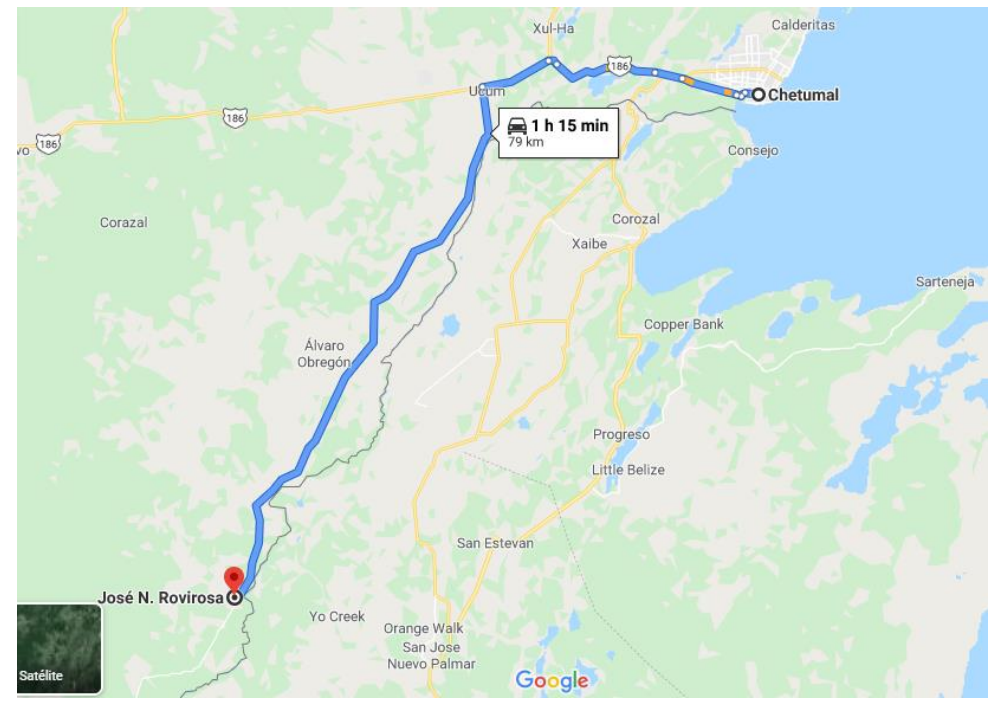

Figura 1. Mapa de localización de la comunidad de José Narciso Rovirosa Nota. 1 Adaptado de Google Maps 2020.

Rovirosa, como le llaman los lugareños, es la localidad número 23 del municipio de Othón P. Blanco de la entidad federativa de Quintana Roo, codificada por el Instituto Nacional de Estadística, Geografía e Informática (INEGI) con el número 230040267, se localiza en el extremo sur del estado de Quintana Roo, en la Ribera del Río Hondo, considerado un poblado tradicional por el INEGI, con altos niveles de marginación social; tiene una población de 1,107 habitantes de los cuales 592 son hombres y 515 mujeres, de este total 544 son sujetos en edad productiva (INEGI, 2016, 2020). 


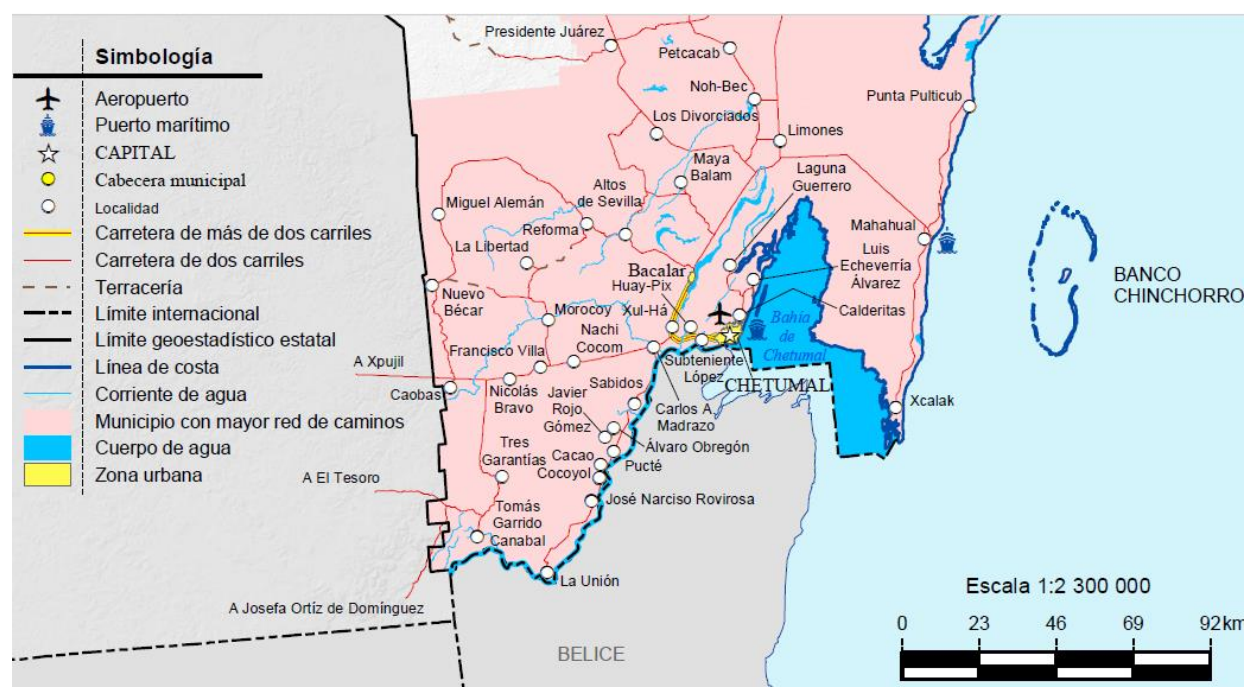

Figura 2. Mapa de José Narciso Rovirosa

Nota. 2 Localización de José Narciso Rovirosa con colindancias. adaptado de INEGI 2016.

Los orígenes de la comunidad de José Narciso Rovirosa están ligados históricamente a la fundación del ejido San Francisco Botes, una localidad de gran importancia forestal que comenzó a finales del siglo XIX en los márgenes del Rio Hondo, por entonces la única vía de comunicación. Los diversos asentamientos instalados a lo largo del Río Hondo son resultado de la colonización dirigida de los años 50 promovida por la federación hacía el estado de Quintana Roo, debido a la abundancia de tierras para el cultivo.

En este contexto se conformó el Ejido San Francisco Botes para dotar de tierras a los campesinos procedentes del centro y norte del país; originalmente las tierras se destinaron a cultivos de auto subsistencia y crianza de animales de patio, pero muy pronto las tierras se destinaron a un programa gubernamental para la producción de caña de azúcar con miras al abastecimiento del entonces naciente Ingenio Álvaro Obregón.

En la actualidad el ingenio es de capital privado y lleva el nombre de San Rafael de Pucté ${ }^{2}$. Desde sus orígenes el ejido está dividido en dos asentamientos diferenciados: los avecindados de la colonización dirigida en uno de los márgenes del río y los históricos asentamientos de población originaria maya en el otro lado.

Una de las comunidad conformada por migrantes provenientes principalmente del centro-norte del país se denominó José Narciso Rovirosa

${ }^{2}$ En México se encuentran 14 grupos azucareros, cada uno con, por lo menos, dos ingenios. El grupo cañero que se encuentra en la zona sur de Quintana Roo (Grupo Beta San Miguel S.A. de C.V.) cuenta con el ingenio San Rafael de Pucté, ubicado en la Ribera del Rio Hondo en el poblado Álvaro Obregón, también conocido como “el Ingenio” (Vega, 2010). 
donde permanece claramente la división entre colonos y población originaria; este ordenamiento territorial responde no solo a razones socioculturales sino en razón de actividades productivas relacionadas con el parcelamiento y sus cultivos: mientras los primeros asumieron casi desde sus orígenes el destino cañero impuesto por la federación como modalidad de producción agrícola, la población indígena maya implementó la agricultura por su histórico arraigo a la tierra como producción de sentido y cohesión social. Así, en zonas llanas, planadas ubicadas entre cerros y lomadas desarrollaron una agricultura de autoconsumo y un incipiente mercadeo local que dista mucho de la producción de los colonos; una diferencia que bien puede suscribirse en el diferendo conceptual entre el territorio como espacio de construcción de sentido y la tierra como medio de producción. ${ }^{3}$

Aunque los colonos mantenían una agricultura de traspatio combinado con la caza y la pesca, lo cierto es que el principal ingreso emanaba principalmente del cultivo de la caña. Las nuevas condiciones derivadas del proceso de privatización del ingenio azucarero en 1988 descargaron los riesgos de la producción ocasionadas por las sequías, incendios o las plagas; aunado a lo anterior, los campesinos debieron enfrentar un complejo circuito de intermediarios para acceder a los incipientes apoyos gubernamentales y asumir los riesgos derivados de las fluctuaciones en los precios de la caña de azúcar sujeta a los vaivenes del mercado internacional, todas estas circunstancias pusieron a los campesinos de Rovirosa en una compleja situación económica que mantiene la comunidad en los escaños más bajos de satisfactores económico e indicadores de desarrollo.

La población cuenta con 323 viviendas particulares habitadas, de las cuales 18 no cuentan con energía eléctrica, 36 no tienen escusado y 30 no tienen agua entubada, 37 solo cuentan con piso de tierra, y 154 viviendas no tiene drenaje. El promedio de la ocupación por cuarto de las viviendas es de 4 personas y en 126 hogares no disponen de un refrigerador; 121 no disponen de lavadora y 331 personas de la comunidad no cuenta con servicio de salud (INEGI, 2013; Semarnat \& Conafor, 2014).

Los resultados en materia de educación indican analfabetismo entre 144 personas mayores de 15 años, 431 no concluyeron el nivel de primaria, y en general, 693 habitantes tienen educación básica incompleta, lo cual incrementa el grado de marginación presente y a futuro pues 33 infantes de 6 a 14 años no asisten a la escuela. El sistema de abasto del poblado tiene acceso

\footnotetext{
${ }^{3}$ Según la FAO la tenencia de la tierra es la relación definida en forma jurídica o consuetudinaria, entre personas, en cuanto individuos o grupos, con respecto a la tierra; es una institución, en tanto conjunto de normas creadas socialmente para regular el comportamiento; en tanto que territorio constituye un referente empírico que alude no solo al espacio físico sino ante todo como espacio de relaciones simbólicas y de construcción de sentido, que fija relaciones de pertenencia y patrones culturales.
} 
a los principales alimentos consumidos por la población de la zona como son: frijol, maíz, arroz, harinas para tortillas, pan de trigo, leche, huevos, pollo, frutas y verduras, sin embargo, el consumo de pescado y carnes de res o cerdo es limitado, los comercios son pequeñas tiendas de abarrotes, una tienda Diconsa ${ }^{4}$, una gasera, una papelería y pequeñas tiendas de ropa y calzado (INEGI, 2013, 2020; Semarnat \& Conafor, 2014).

Debido a estas condiciones los colonos de Rovirosa han emprendido de manera alternada diversas modalidades de desplazamiento hacia el norte del Estado, especialmente a las ciudades de Cancún, Tulum y Playa del Carmen para trabajar en las actividades de la industria de la construcción y los servicios turísticos. Curiosamente este proceso de descampesinización que había dado inicio con estos desplazamientos dio un viraje y los labriegos volvieron a las labores del campo y la intensidad agrícola, pero no en la comunidad sino en las farmas de Canadá a través del programa PTAT.

La mayoría de los colonos son ejidatarios o hijos de ejidatarios, se puede adquirir un título de propiedad ejidal, porque está vigente esta figura de tenencia colectiva de la tierra ${ }^{5}$ la disponibilidad de tierras también ha permitido la compra, acumulación y procesos de privatización de la tierra.

El ejido permite que tú puedas sembrar si quieres. La gran mayoría de la gente vive de la caña de azúcar, es rentable cuando vale, pero como es un cultivo de temporada, y si sale mal, si hay sequía, incendios, los riesgos son del trabajador. También hay pérdidas por tabulación y fluctuación del precio, también afecta; el riego es de pozo, pero es con permiso y eso solo se lo dan al que tiene poder. Si el precio del azúcar baja, pues también sales afectado. Aquí hay tierra, demasiada tierra y es barata y buena tierra, pero de poco te sirve si no tienes capital y si tienes no puedes sembrar lo que quieras y si puedes hacerlo, el precio al que te compran, es tan bajo que no vale la pena: Un señor de aquí tiene contrato con la Costeña ${ }^{6}$, él siembra chile, ellos vienen por la producción, pero la Costeña les paga $\$ 4.00$ por kilo, es mucho trabajo para sacar tan poco. Los que no tienen tierra o no se quieren endeudar con el ingenio se van de cortadores de caña; allí, por ese trabajo te pagan 1,500 pesos a la semana, para uno con familia es muy poco y mucho desgaste, pero siempre hay gente que vive peor; la gran mayoría de los cortadores de caña son de aquí; llegaron a la comunidad atraídos por ese trabajo y se fueron quedando; de esa manera el ingenio dispone siempre de cortadores de caña. Cuando no dispone es porque la gente se ha ido a Cancún o a Playa a trabajar y entonces es cuando contratan centroamericanos o esporádicamente a beliceños, pero para ellos no es muy rentable venir a México, allá en Belice pagan en dólar y la zafra es todo el

\footnotetext{
${ }^{4}$ Diconsa es una red de abasto social en México, que trabaja para garantizar la distribución de alimentos económicamente accesibles, para la población en condiciones de marginación. Opera el Programa de Abasto Rural con más de 27 mil tiendas fijas y 300 móviles en todo el país.

${ }^{5} \mathrm{La}$ forma de producción del ejido, es una de las modalidades de tenencia de la tierra que configuran la propiedad social agraria, la otra, es la tenencia comunal una de las piezas fundamentales de la estructura social del país.

${ }^{6} \mathrm{La}$ costeña es una empresa mexicana con presencia en varios países del mundo que manufactura y distribuye conservas, encurtidos, vegetales, sopas, caldos y salsas italianas
} 
año. Las condiciones son muy duras, por eso la gente se va porque no hay manera de ganar. Somos ejidatarios, pero ¿de qué te sirve la tierra?.

\section{Programas de empleo, México-Canadá}

En Canadá, la existencia de los programas de empleo temporal surge en 1960 con la contratación de trabajadores de otras provincias del país a través de un programa denominado Canadian Clearance Program, sin embargo, para 1966, el programa ya incluía trabajadores de las Antillas procedentes de países como Jamaica, Barbados y Trinidad y Tobago, no obstante, durante el periodo de 1970 a 1983 se formó un programa bajo la supervisión del Canada Farm Labour Pool Program que abrigó a estudiantes canadienses para trabajar en los cultivos de tabaco de manera temporal, a estos, posteriormente se unieron estudiantes europeos y estadounidenses. Estas modalidades de empleo temporal pueden considerarse como el antecedente del Programa de Trabajadores Agrícolas Temporales (PTAT) para la contratación de mano de obra internacional para trabajar en el sector de la agricultura.

México ingresó al programa en el año de 1974 con la firma de un convenio bilateral que establecía un Memorándum de Entendimiento entre los gobiernos de Canadá y México; en sus inicios contó con la participación de 203 trabajadores que llegaron a laborar temporalmente en los campos agrícolas de nueve provincias canadienses, Alberta, Columbia Británica, Isla del Príncipe Eduardo, Manitoba, Nuevo Brunswick, Nueva Escocia, Ontario, Quebec y Saskatchewan (CONSULMEX, 2017, 2017; Durand, 2006).

Aunque la contratación de trabajadores caribeños duplicó entre 1980 y 1991 el número trabajadores internacionales en el agro canadiense, la participación de los mexicanos, en 1991, había aumentado un $600 \%$ con un total de 5,148 trabajadores, lo que representaba el 43\% de la participación total de fuerza de trabajo extranjera en el programa, esto revela que desde sus inicios hubo una aceptación positiva de los empleadores canadienses con respecto a los trabajadores mexicanos, en apariencia porque en los años noventa, el problema principal de los cultivos de Ontario era la rotación constante de los trabajadores agrícolas y la falta de mano de obra en los momentos de mayor demanda, por lo que la llegada de los trabajadores mexicanos estacionarios fue la solución idónea para los empleadores ${ }^{7}$.

En Canadá, el PTAT se privatizó en 1987, en consecuencia, el manejo del programa dejó de ser gestionado por entidades gubernamentales y quedó en manos de organizaciones como la Forengein Agricultural Resource

${ }^{7}$ Para una exposición sucinta véase Durand, Jorge (2006) Programa de trabajadores temporales: Evaluación y análisis del caso mexicano, Secretaría de gobernación, México. Verduzco, Gustavo (2015) El PTAT y los programas de trabajadores temporales. Una visión crítica, CLACSO, B/Aires, Argentina 
Management Service (FARMS) y la Fondation des Entrepriese en Recrutement de Maind-d'oeuvre Agricole (FERMES) que aglutina empresarios agrícolas canadienses; mediante estas organizaciones los empresarios canadienses o propietarios de granjas, conocidas popularmente como farmas, presentan una solicitud en concordancia con la cantidad de trabajadores necesarios para satisfacer los requerimientos de fuerza de trabajo a empresarios del agro canadiense o propietarios de granjas.

En México, por el contrario la gestión del programa continuó a cargo de la Secretaría del Trabajo y Previsión Social (STPS), que tiene dentro de sus funciones la difusión del programa de movilidad laboral, el reclutamiento del personal y la posterior distribución de los trabajadores en las granjas canadienses, así mismo, realiza los trámites conducentes para el empleo temporal como la solicitud de pasaporte, verificación de exámenes médicos, solicitudes de las visas, trámites de boletos y el registro de las solicitudes de trabajo ante las asociaciones de empleadores; la intensidad y dinamismo del programa ha llegado a gestionar y tramitar, en el 2010, 15,809 solicitudes de trabajadores aspirantes y su inserción en 1,488 farmas.

La demanda de mano de obra por parte de los empleadores canadienses, es trasmitido al gobierno, cada temporada agrícola, Las personas que aspiran al empleo deben cumplir con el siguiente perfil: nacionalidad mexicana; conocer y demostrar destrezas en las labores agrícolas; tener de 22 a 40 años de edad; no tener limitaciones físicas y tener buena salud; tener pareja o dependientes económicos; escolaridad mínima primaria y máximo primero de bachillerato; radicar en una zona rural y no contar con antecedentes penales en México, Estados Unidos y/o Canadá (CONSULMEX, 2017).

Los empleadores canadienses están comprometidos a proporcionar a los trabajadores viviendas que cumplan con los requisitos mínimos habitables y a equipar la vivienda con aparatos electrodomésticos, así mismo, suministrar alimentos. Sin embargo, tanto la vivienda como la alimentación tiene gravamen para los migrantes que retiene el patrón de los respectivos ingresos de cada trabajador. El contrato debe cubrir los costos de viaje aéreo, la seguridad social y el seguro de vida durante la vigencia del mismo. No obstante, los empleadores cobran a los trabajadores el pago adelantado a través de las deducciones descontadas en el salario.

La migración circular México-Canadá-México es una de las alternativas propuestas por el gobierno para proveer a las farmas de fuerza de trabajo, aliviar la crisis del sector primario y solventar la demanda de empleos, es importante señalar que quienes se insertan en el programa, permanecen de seis semanas a ocho meses en las provincias canadienses sin posibilidad de prorrogar su estancia, no tienen derecho a pedir un cambio de forma migratoria con miras a la permanencia, ni derecho a la reunificación familiar; también 
está excluido del programa PTAT que el trabajador pueda pedir asilo político o refugio.

A cincuenta años de la implementación del modelo PTAT es posible reconocer las asimetrías en la relación costo-beneficio, mientras Canadá se ha convertido uno de los países agroexportadores más importantes del mundo, fundamentalmente, merced a la explotación de fuerza de trabajo de los jornaleros agrícolas mexicanos, en cambio no existe un marco jurídico para la protección de los trabajadores, de hecho, es posible afirmar que justamente la ausencia de un marco jurídico es lo que convierte en moneda de cambio los derechos de los migrantes favoreciendo su explotación y violación a sus garantías laborales.

\section{Antecedentes: Los nortes}

El dinamismo migratorio de los trabajadores agrícolas mexicanos al norte tiene una vieja data: la que se ha movilizado históricamente en gran medida por la vecindad con los Estados Unidos, conocida eufemísticamente como el norte y otra más reciente hacia Canadá designada como el otro norte.

A lo largo del siglo XX y derivado de los pulsos en materia de asuntos migratorios entre México y Estados Unidos, los campesinos migraron mayoritariamente en condiciones irregulares o de clandestinidad; un proceso marcado por graves abusos a los derechos humanos tanto en el cruce fronterizo como en los nichos laborales a donde lograron insertarse. Sin embargo, hubo ingresos y salidas de población reguladas por ambos países, en razón del déficit de fuerza de trabajo en el norte y la falta de empleo en México.

En un importante ejercicio de sistematización de este dinamismo migratorio, Jorge Duran $(2006)^{8}$ ha reconocido seis momentos importantes hacia el norte con ciclos temporales de 20 años aproximadamente, pautados por ritmos de apertura y cierre de los flujos. El desarrollo de estas fases inicia con 1. "La era del enganche 1884-1920" un proceso resultante de dos momentos diferentes pero complementarios: por un lado, la ley de exclusión de la inmigración china y japonesa aprobada en el Congreso de los Estados Unidos en 1882, y, por otro lado, las contiendas en el marco de la Revolución Mexicana que se convirtieron en un importante factor de expulsión. Ambas circunstancias propiciaron el reclutamiento internacional de mano de obra mexicana para trabajar en los campos norteamericanos que demandaban fuerza de trabajo de forma urgente y perentoria. 2. "Deportaciones, reenganches y migraciones masivas (1921-1941)" refiere un proceso derivado de la crisis económica y las políticas de retraimiento en los Estados Unidos,

\footnotetext{
${ }^{8}$ Véase Durand J. (2006). Programa de Trabajadores Temporales: evaluación y análisis del caso mexicano, Ed, CONAPO.

http://www.conapo.gob.mx/en/CONAPO/Programas_de_trabajadores_temporales_Evaluacion_y_anali sis_del_caso_mexicano_2007
} 
que tuvo como contraparte una política gubernamental de repatriación abanderada primero por el presidente Álvaro Obregón y posteriormente bajo el gobierno del presidente Lázaro Cárdenas. 3. "El Programa Bracero 19421964" es el tercer periodo, inscrito históricamente en el marco de la II Guerra mundial, y la demanda y reclutamiento de trabajadores mexicanos para el mercado laboral agrícola.

Este programa será punto de referencia en esta investigación, como veremos más adelante, pues permite identificar por un lado los orígenes de una modalidad de desplazamiento de la fuerza de trabajo rural en condiciones de una legalidad temporal marcada por los ciclos agrícolas, por otro lado, es referencia para reconocer el tránsito de flujos migratorios bajo la tutela de los estados nacionales al outsourcing, que caracteriza, en la actualidad, los procesos de reclutamiento de fuerza de trabajo mexicana hacia Canadá, en manos de particulares o entidades privadas.

En efecto, el Programa Bracero es un acuerdo bilateral entre México y Estados Unidos, considerado como un modelo, en el sentido de tipo ideal de desplazamiento que favorecía a ambos países, Estados Unidos se beneficiaba de la fuerza de trabajo para el campo y el mantenimiento de las vías ferroviarias; en tanto que para México significaba desahogo de presiones económicas, ya que recibía el beneficio de las remesas que enviaban los jornaleros a sus familias. El programa, sin embargo, no logró satisfacer la oferta y la demanda de fuerza de trabajo por los causes acordados entre los dos Estados, lo que generó un río paralelo de labriegos indocumentados contratados en condiciones abusivas, toda vez que estaban desprovistos de protección gubernamental. El cierre del programa en 1964 da apertura a una cuarta fase, señalada por Durand (2006) como 4. La era de "los Indocumentados 1965-1986". La ausencia de una política migratoria y una "dinámica causal acumulativa" se tradujo en la movilización de un capital social que permitió que los trabajadores generaran sus propias redes para el cruce migratorio y el abastecimiento de fuerza de trabajo en el norte; la relación trabajador-empleador también se realizó de manera clandestina de espaldas a las restricciones de la política migratoria en el interior del territorio norteamericano. 5. "La era bipolar 1987-2007" tuvo diversos picos e intensidades para el control de los flujos migratorios y el resguardo de las fronteras; la migración en este periodo empieza a perfilarse como un asunto de soberanía o de seguridad nacional. 6. La última fase, "la batalla por la reforma migratoria 2007-2014" pone en juego, junto a la dinámica migratoria el aspecto legal y el aspecto económico. Hasta este momento el problema más acuciante para los trabajadores era el cruce: alcanzado "el otro lado", la permanencia no estaba en cuestión, sin embargo, la inflexibilidad de la política migratoria en Estados Unidos se hizo extensiva hacia el estatus legal de la permanencia de los trabajadores. Aunado a lo anterior, las crisis económicas 
y políticas de los países centroamericanos generaron flujos migratorios hacía los Estados Unidos que compitieron por los nichos laborales históricamente ocupados por mexicanos (Durand, 2006).

Todos estos elementos en su conjunto, ligados a la precarización laboral y la crisis del empleo bajo el régimen del modelo neoliberal, han propiciado nuevas formas de contratación de carácter eminentemente privado, bajo el apotegma de la libre contratación entre un trabajador libre que vende la fuerza de trabajo y un empleador que la compra en un mercado cambiario.

A diferencia de la migración de mexicanos a los Estados Unidos, la migración de connacionales a Canadá es relativamente nueva, esto, sin duda, responde al distanciamiento geográfico y a políticas de apertura de Canadá para recibir fuerza de trabajo temporal para la inserción de empleos de baja cualificación laboral. Este dinamismo poblacional se inicia en los años 70, con población mexicana calificada académicamente que vive en condiciones de regularidad migratoria, con cifras opuestas a la inmigración calificada en los Estados Unidos. Empero, existe un flujo más dinámico que migra a Canadá con contratos temporales para trabajar en la agricultura; la modalidad de estos contratos, como veremos en este trabajo, impide que, a diferencia de la migración a los Estados Unidos, desde el Programa Braceros, imposibilita la permanencia de los trabajadores en el otro norte.

Las diversas modalidades de contratación indicadas por Durand (2006) reconocen, en términos del modelo clásico sobre las migraciones, push-pull un país emisor y receptor, la demanda de fuerza de trabajo en el campo del norte (Estados Unidos) y el otro norte (Canadá) al punto que puede indicarse que la seguridad alimentaria y la boyante industria agrícola de estos países ha dependido y de hecho sigue dependiendo de la fuerza de trabajo internacional; en tanto, los países en desarrollo no sólo son expulsores de fuerza de trabajo, de cuyas remesas depende una parte muy importante de los PIB nacionales, y sin embargo, no están en condiciones de negociar contrataciones reguladas, que sería lo conducente entre dos Estados soberanos, con fines a la protección legal de los trabajadores migrantes. Esto sin duda encuentra su explicación, no sólo en las desigualdades propias de la división internacional del trabajo, y la hegemonía de los países del norte, dicho lo cual, por estas circunstancias los trabajadores han quedado a merced de contrataciones irregulares, salarios precarios, extenuantes jornadas de trabajo y sin seguridad social, expuestos, además, a las persecuciones dictadas por una normatividad que los atrae, repele y expulsa a conveniencia.

Bajo este marco histórico la presente investigación realiza un recorrido conceptual sobre el vínculo entre migración circular y gestión de poblaciones; seguidamente se exponen los resultados empíricos de la experiencia migratoria circular que realizan los labriegos de la comunidad de José Narciso Rovirosa, que migra circularmente a trabajar a las farmas de Canadá. Se parte 
de tres hipótesis principales: 1. Que la migración circular es el patrón migratorio del capitalismo global para la apropiación de fuerza de trabajo y la maximización y rentabilidad sobre los cuerpos y la vida. 2. Que la dinámica del capitalismo, a través del monopolio y monocultivo de la caña de azúcar en el sur de Quintana Roo, no permite a los labriegos ni la explotación de sus tierras, ni el emprendimiento, -justificante principal de la migración circularde los trabajadores con miras al desarrollo local.

\section{Gestión de Multitudes, EL PTAT}

La participación del Estado en el proceso migratorio como regulador de los métodos de contratación ha propiciado un elevado número de acuerdos firmados, los trabajadores se adaptan a las características de la oferta y la demanda y toman a estas migraciones de ida y vuelta como una alternativa laboral, mientras que para el Estado representa un recurso político que persigue el objetivo de suministrar fuerza de trabajo a la agroindustria en sus sectores y líneas de producción, y evita la migración indocumentada, por lo que algunos organismos internacionales promueven la migración circular temporal como una alternativa innovadora y eficaz para la regulación del flujo de trabajadores internacionales.

Las condición jurídica y regularizada que brinda esta forma de migración que cuenta con un permiso de estancia y trabajo se considera la mayor ventaja para el trabajador temporal, esta circularidad sugiere -como se indicó- que los vínculos afectivos y emocionales de los trabajadores y sus familias no se alteran en el ejercicio de esta movilidad; además, plantea que los trabajadores temporales son potenciales agentes de desarrollo en tanto generadores de remesas que pueden ser invertidas en la localidad de origen y en razón de los conocimientos adquiridos y su capacidad de transferencia. Las desventajas surgen a partir de la falta de libertad del trabajador y las sanciones producidas por el desacato al sistema contractual que los rige y la posición que adquieren como mano de obra mercantil (Achón Rodríguez, 2011; Castellanos, 2014; Fargues, 2008; Zapata-Barrero et al., 2012).

La condicionalidad del retorno, constituye la identidad principal de la migración circular: destinada a gestionar los flujos, facilitar la explotación de la fuerza de trabajo y salvaguardar la competitividad del empresario, tiene como condición impedir el asentamiento y asegurar el retorno del trabajador a su lugar de origen, por lo que, como se ha venido indicando, la residencia, la ciudadanía, el asilo político y la reunificación familiar están derogadas en este patrón migratorio; paralelamente debido al carácter temporal de su estancia para trabajos específicos, el trabajador solo se encuentra en el territorio canadiense por temporadas específicas y mayoritariamente dentro de las farmas, este condicionamiento y aislamiento del trabajador impide la cohesión con la sociedad receptora. A pesar de que la migración circular se 
plantea como una alternativa beneficiosa para ambos países, es claro que los beneficios son dispares entre Canadá y México y lleva implícito la perdida de los derechos laborales y políticos de los trabajadores.

Dentro de las ventajas de la migración circular para el país emisor se destacan dos aspectos: 1. La disminución de las demandas internas de empleos y salarios y 2. La captación de remesas económicas que impactan en el PIB. Para los países desarrollados la migración circular representa la solvencia del déficit de fuerza de trabajo y el control sobre la estancia y permanencia del trabajador, ambos aspectos se traducen en el crecimiento económico y la maximización y la pujanza de las empresas en los rubros de la agroindustria. Las agencias estatales promocionan la migración circular como un ejemplo de buena práctica, al considerar que este patrón migratorio, además de solucionar las necesidades del mercado laboral y ordenar los movimientos migratorios, impulsa el avance económico y social de los países expulsores (López \& Serrano, 2020).

En el caso de México, la migración circular asociada con trabajadores temporales que cada año viajan a Estados Unidos, forma parte del Programa Trabajadores Huéspedes, que expide visados para empleo agrícola (H-2A), y para empleos no agrícolas (H-2B). Esta gestión colectiva de contrataciones en origen, forma parte de políticas de apoyo para que las empresas estadounidenses, cubran puestos que son socialmente necesarios, pero considerados fatigosos, peligrosos o degradantes para la población local (Bauer \& Stewart, 2013; Castellanos, 2014). Sin embargo, la razón principal de la contratación de fuerza de trabajo migrante es su rentabilidad que se manifiesta en la disparidad de los salarios y garantías sociales entre éstos y los trabajadores locales.

Es en la cantidad de horas a las que son sometidos los inmigrantes y los bajos costos, su fácil reemplazo sin consecuencias en materia de seguridad social, donde reside el beneficio de la contratación y de donde el capital extrae sus máximos beneficios económicos. Aunque en teoría los empresarios deben solicitar trabajadores procedentes de países con economías en crisis demostrando que no existe personal disponible ni residente ni local, lo cierto es que los migrantes son contratados por los beneficios de explotar la fuerza de trabajo como mercancía, como valor de uso, encarnación del potencial generador de riqueza en condiciones de bajo costo en precariedad y el hecho de extraer de ellos su máxima rentabilidad.

\section{Migración circular y rentabilidad de la fuerza de trabajo}

La intimidad del vínculo entre globalización y migración ha sido reiteradamente referenciada por autores como Jumilla (2002), Suárez (2008), Dávila (2019), Raghavan (2004) y Garrido (2004), sin embargo, en sí misma la interconexión de regiones distantes del mundo no causa directamente la 
migración, es la liberación de los mercados, la integración de las economías nacionales a los mercados internacionales, así como los procesos de privatización de la economía, la dislocación de la política y la economía; y, subsecuentemente, el reducido margen de maniobra de los Estados para responder a las demandas de los ciudadanos en los respectivos territorios, lo que ha convertido la migración, tanto a nivel nacional como internacional, en la única opción de las personas para solventar sus necesidades básicas (Bauman, 2004; Sassen, 2003; Jumilla, 2002; Suárez, 2008; Dávila, 2019; Garrido, 2004; Raghavan, 2004).

La desregularización de la economía, su carácter hegemónico y supranacional, ha convertido el empleo en un bien escaso y ha exacerbado las diferencias y las desigualdades entre países, mercados e individuos; es en este contexto donde las personas optan por la emigración hacia polos de atracción laboral, por lo tanto, más que el vínculo entre globalización y migración lo que se observa es la estrecha relación entre la producción capitalista y los flujos migratorios. La globalización más que causante de los dinamismos migratorios lo que ha creado son las condiciones para el reclutamiento de la mano de obra en cualquier parte del mundo en razón de su rentabilidad para la producción; en otros términos, es el carácter transnacional de la economía lo que permite que las empresas puedan reclutar mano de obra de origen inmigrante sin los costos de la contratación de trabajadores locales, evitando de paso, las consecuencias del asentamiento de los migrantes.

La crisis económica global, en efecto, ha generado una sobre oferta de trabajadores procedentes de países en desarrollo que ven la migración como la única vía de subsistencia; las empresas, por su parte se han beneficiado de esta circunstancia para el aumento de utilidades mediante la contratación de esta fuerza de trabajo, en condiciones precarias y de bajos salarios; no obstante, para los países receptores, aun reconociendo los beneficios de captación de mano de obra internacional, intentan contener su afluencia, y el arraigo de los trabajadores, al ser considerados como una gran amenaza para la población nativa, en este escenario la gestión de los flujos migratorios es un asunto de seguridad y de soberanía de los Estados nacionales.

La migración circular se convierte, en este contexto, en un patrón de movilidad idóneo en la medida en que permite el ingreso legal de trabajadores, pero con restricciones para la libre circulación y durante periodos estrictamente determinados, a la vez, cumple con el objetivo de alimentar de mano de obra internacional a las empresas a efectos de promover su competitividad y rentabilidad. Este tipo de gestión para el desplazamiento y rentabilidad de la fuerza de trabajo se realiza a través de programas de empleo temporal que reviste formas neocoloniales de acceso a la fuerza de trabajo: el préstamo o adelanto de recursos económicos para el trámites de visado y pasajes permite el aseguramiento de una relación laboral patrón-trabajador, sin 
agravios para el primero, pues el desembolso otorgado será descontados progresivamente del salario del trabajador durante el tiempo de permanencia en los nichos laborales.

La implementación de este patrón de movilidad es acorde al modelo neoliberal que ha agudizado las asimetrías entre regiones y países, y va en detrimento de los derechos laborales de los trabajadores. Sin embargo, aunque este modelo de desplazamiento es una característica del modelo económico actual, es preciso reconocer que la migración circular es un fenómeno de vieja data que ha estado presente en distintos países y continentes, siempre en función de proporcionar mano de obra para la producción capitalista. Lo distintivo de la circularidad en el siglo XXI es su tendencia a la repetición, salida y regreso. Las migraciones circulares conforman un caso específico en el marco de las migraciones temporales y pueden ser definidas como una forma de migración gestionada de manera tal que permite un cierto grado de movilidad legal de ida y vuelta entre dos países (Zapata Martelo et al., 2010).

En ese sentido refiere a un sistema que facilita la migración de forma circular ida-vuelta y su renovación cíclica entre un país de origen y uno de destino que demanda fuerza de trabajo cualificada o no cualificada para la inserción laboral en diversos rubros de la economía y la producción.

En suma, en esta investigación se ha de comprender la migración circular como aquella movilidad económica que responde a las necesidades de mano de obra y a la lógica de competencia global y de producción flexible, que se desplaza temporalmente, de forma cíclica y repetitiva entre dos o más países, con un visado restringido para una actividad acotada y un rango temporal que impide al trabajador la posibilidad de residencia permanente en el país receptor. La migración circular hace referencia a acuerdos bilaterales entre uno o varios países para el reclutamiento y aprovechamiento de mano de obra en condiciones de precariedad. Los trabajadores que participan de esta movilidad laboral, son migrantes que viajan con un visado que acredita el desplazamiento y su inserción laboral. En este tipo de convenios la fuerza de trabajo entra en calidad de insumo para la producción, sin otros derechos más que los de la propia reproducción de la fuerza de trabajo; en esta movilidad hay un estricto control sobre la temporalidad, y la movilidad del trabajador; dos factores que le impiden el arraigo o emplearse libremente, por tanto, este control no faculta al trabajador para que pueda ser abrigado por las normas vigentes de los trabajadores locales.

Desde el marxismo, el término fuerza de trabajo es un insumo de la cadena productiva que el Estado-nación provee, pero en los nuevos modelos de producción pasa a ser un insumo desechable. Por ello, al nuevo orden social no le importa la integración del inmigrante. Al mismo tiempo, el trabajador internacional móvil tampoco se concibe o identifica como clase social de un sector laboral (Castellanos, 2014). 
En la circularidad necesariamente deben revisarse las implicaciones y efectos de la movilidad en el espacio entre las comunidades de origen y destinos porque las personas siguen ligadas a los lugares donde mantienen relaciones vitales. En este sentido, la clasificación del migrante temporal que alude a aquellas personas que no cambian el lugar de residencia es impreciso para designar las características del migrante circular. La circularidad se identifica como patrón migratorio y no como etapa de un proceso. Los aspectos que distinguen la movilidad son un círculo definido por salidas y retornos, que se puede volver repetitivo. La alternancia de estancias entre el aquí y el allá, excluye las siguientes combinaciones, propias de otros procesos migratorios: que en el futuro la persona elija residir en el país de origen o en destino, suspenda el viaje cuando las leyes ya no le favorezcan o se jubile y decida establecerse en cualquier lugar como no sea su lugar de origen.

\section{Migrante, trabajador temporal}

La naturaleza de los procesos de la globalización no regulada y políticamente incontrolada ha generado zonas indefinidas, una suerte de free zone, desde el punto de vista legal que ha afectado de forma contundente a los trabajadores temporales internacionales. En efecto, el concepto o la figura de migrante temporal está vinculado al de trabajador temporal que, previa una contratación, realiza un trabajo determinado con una temporalidad definida; el binomio migrante-trabajador temporal hace parte del proceso dinámico de la globalización, pero, es preciso indicar que no existe un marco político adecuado para su designación en ninguno de los polos de atracción migratoria ni en Europa, Estados Unidos o Canadá. Esta ausencia en la legislación trae aparejada una especie de "vulnerabilidad garantizada"; el trabajador es incluido en un proceso productivo, pero permanece exento de derechos lo mismo en el plano migratorio como en el plano laboral está ausencia de estatus en la legislación favorece la violación de los derechos sociales de los migrantes circulares, y propicia que los derechos laborales se conviertan en moneda de negociación.

Por ello, en opinión de Zapata-Barrero et al. (2012), la figura del Trabajador Temporal plantea retos importantes para su definición y reconocimiento dentro de los marcos jurídicos, políticos y sociales, que vayan más allá de la gestión transitoria. La restricción de derechos del Trabajador Temporal se debe a los vacíos legales que definen la circularidad como un tránsito y no como lo que realmente es, un patrón migratorio definido por su condición de movilidad permanente (Castellanos, 2014; Zapata-Barrero et al., 2012). Las personas que participan de ella permanecen fuera de los parámetros legales, sus derechos son estrictamente seleccionados y parciales, en contraste con los nativos y los inmigrantes permanentes. 
El Trabajador Temporal no es beneficiario de políticas o programas dirigidos a la comunidad extranjera, porque no son parte de ella. Incluso dentro de la sociedad civil, no participa en asociaciones de inmigrantes o en sindicatos, como lo muestran las distintas investigaciones realizadas por Anchon (2011), Fargues (2008), Gordo (2008), Gualda (2012) y ZapataBarrero (2012). La falta de protección, tanto de los países de origen como en los de recepción, convierte la mano de obra internacional en una multitud que puede ser requerida o desechada según las necesidades económicas. Este patrón migratorio responde fundamentalmente a un proceso de apropiación de fuerza de trabajo de países en desarrollo para la maximización y rentabilidad de las empresas en los polos de atracción migratoria (Achón Rodríguez, 2011; Fargues, 2008; Gordo, 2008; Gualda, 2012; Zapata-Barrero et al., 2012).

\section{Gestión y rentabilidad de fuerza de trabajo}

En los lineamientos de operación publicados en el 2016, por la Secretaria de Trabajo y Previsión Social (STPS) para el Programa de Trabajadores Agrícolas Temporales México-Canadá (PTAT), la Subsecretaría de Empleo y Productividad Laboral en coordinación general con el Servicio Nacional de Empleo, señalan que, El PTAT es gestionado como una alternativa de ocupación temporal, ordenada, y legal dirigida a los agricultores de las comunidades que deseen realizar una movilidad laboral como trabajadores agrícolas en Canadá, el país ofrece, de acuerdo a lo estipulado en el convenio, respeto de los derechos laborales y condiciones de trabajo igualitarias a los connacionales, con esto se busca satisfacer la demanda de empleo por parte de la población agrícola y en conjunto, satisfacer las necesidades de mano de obra por parte de los empleadores canadienses.

En este contexto se plantean dos objetivos generales acorde al patrón de movilidad circular: 1) vincular a los trabajadores agrícolas mexicanos con las oportunidades de empleo que se generan en el mercado de trabajo agrícola canadiense, a través de un modelo de movilidad laboral de carácter legal, ordenado y seguro, cumpliendo con el perfil requerido por los empleadores canadienses. 2) Se busca beneficiar a la población agrícola con mayores carencias económicas y al mayor número de familias posible, procurando evitar la concentración del beneficio en grupos familiares, municipios o zonas geográficas determinadas del país. (Subsecretaría de Empleo y Productividad Laboral et al., 2016)

El auge en la promoción y difusión del Programa de Trabajadores Agrícolas Temporales en la Ribera del Río Hondo inició en el 2006, vinculada a la campaña presidencial de Enrique Peña Nieto, por el Partido Revolucionario Institucional, PRI; un trueque clientelar que a cambio del voto electoral, los campesinos tenían garantizado el ingreso al PTAT; debido a las 
condiciones imperantes en la zona, "todos votaron y todos se alistaron (...) todo el pueblo se fue".

La mayoría se enteraron por la radio que emitía desde Chetumal, en ese tiempo no había celulares ni nada, Yo me enteré por un compañero, estábamos en la milicia y en las guardias calculábamos: ¿dejar la milicia y meterse al PTAT? esa era la cuestión y la decisión sí daba miedo; y nos hablábamos para darnos valor, daba miedo porque no sabes qué patrón te va a tocar; al mero principio los primeros que se fueron de Quintana Roo eran soldados, después con Peña Nieto se corrió la voz y todos los campesinos se engancharon, todo el pueblo se fue.

Ante la urgente demanda de trabajadores para las farmas canadienses, el PTAT básicamente exigía a los postulantes tener experiencia en el agro. En efecto, advierte un funcionario del PTAT que, desde el inicio del funcionamiento del programa y hasta el 2005 no se realizaba un examen, sin embargo, el programa empezó a tener un impacto negativo ya que muchas personas aceptadas para viajar a trabajar a Canadá no tenían las competencias ni las habilidades que exigía el intenso trabajo en las farmas canadienses; con estas consideraciones en el 2014 se implementó un examen de conocimientos relacionados con el agro que se empezó a aplicar a los aspirantes a través de una plataforma denominada $\mathrm{SIMOL}^{9}$, misma que, también realiza un registro de los datos generales de los trabajadores.

Los exámenes se empezaron a hacer porque llegaba gente que no sabía nada del campo. Al principio no te pedían estudios, es más, entre menos estudios tuvieras, más posibilidades tenías de ser contratado, tampoco te pedían que supieras inglés o que supieras otro idioma. Lo importante es que te pudieras comunicar y que enseñaras tus manos para ver si era verdad que sabías trabajar en el campo, si estaban tus manos bien encallecidas era pasaporte directo. Pero por el desempleo y la mala paga se alistaron hasta gentes con estudios, ingenieros forestales o agrícolas o gente que sabía muy poco del campo y al llegar allá - a las farmas- había problemas, había gente que no sabía ni agacharse para quitar la maleza o cosechar. Eran gente de ciudad, trabajadores de almacenes, vigilantes o de fábricas, no tenían ni idea y el campo es pesado.

Por eso ahora te hacen examen de aptitudes, que son requerimientos de los patrones de lo que necesitan allá; las preguntas vienen de allá, y yo creo que está mal, porque acá no sembramos fresa, manzana, y menos sabemos cuántas toneladas rinde una hectárea de fresa, de lechuga. En cada Estado de Canadá es diferente, y deberían preguntar de acuerdo a la experiencia del trabajador. Cada vez la ponen más difícil, Pero ya no quieren más muchachos de Rovirosa, porque son los que más viajan a Canadá. La población joven ya no tiene mucho chance de irse a Canadá.

${ }^{9}$ SIMOL, plataforma del Sistema de Movilidad Laboral utilizada para el registro de los trabajadores temporales mexicanos que hacen la movilidad laboral a Canadá. 
Originalmente el programa otorgaba a los trabajadores seleccionados, a través de esta nueva modalidad, un apoyo de $\$ 3000.00$ (tres mil pesos mexicanos) para cubrir los gastos por concepto de exámenes de salud en clínicas oficiales del sector salud en la Ciudad de México, para garantizar el óptimo estado de salud de los solicitantes ${ }^{10}$. Adicionalmente, el empleador cubría los gastos administrativos y de traslado, sin embargo, muchos de los postulantes, que aún, después de realizar todo el proceso terminaban desistiendo de viajar a Canadá este beneficio se derogó pues reflejaba una pérdida para los empleadores. En la actualidad los trabajadores cubren los gastos de los trámites, como el pasaporte y permiso de trabajo en los que el gobierno mexicano otorga un descuento, el traslado es cubierto por el empleador y posteriormente descontado al trabajador durante su estancia laboral.

El trabajador paga también la renta, la comida, no nos quitan mucho, pero si pagamos 30 dólares quincenales de renta en algunas partes. En Ontario, Ottawa y Quebec, la mayoría de los que estamos aquí está en Ontario, allá se gana 14.38 la hora, 14.25, dólares canadienses. La gente se aguanta muchos abusos porque ha invertido en el viaje; el proceso migratorio es la inversión para salir de pobres. Antes no se pagaba por la visa o el permiso de trabajo, antes nos daban un dinero para ir a México, para todos los gastos; el apoyo lo daba la secretaría, pero ya ahora no. La cuestión es que también el gobierno o la secretaría nos quita uno o dos dólares por hora. La hora cuesta doce dólares, pero el gobierno se queda con dos dólares, entonces en realidad nos pagan 10 dólares. Tienen que recibir porque de dónde sacan para hacer los trámites, te dicen que son gratis, pero ellos sacan de ahí mismo, de lo que trabajamos nosotros para mantener el programa.

El primer trabajador de la comunidad que entró a trabajar a través del PTAT data del 2004, sin embargo, como afirman las migrantes circulares entrevistados, en las farmas han conocido trabajadores que llevan 30 temporadas, tres generaciones migrando a Canadá: abuelo, padre, e hijo. Sin embargo, hay diferencias notables, la primera y segunda generación permanecía dos o tres años en Canadá o el tiempo que quisiera mientras tuviera trabajo y después regresaba a México, al hijo le tocan otras condiciones, migrar a través del PTAT y los tiempos y las condiciones las dicta el programa, con modalidad restringida y sin posibilidad de arraigo; es posible hablar, en estas condiciones de una dinámica causal acumulativa, en el sentido de la persistencia de movilidades poblacionales circulares hacia el exterior, sin embargo, su recurrencia e incidencia indican que las condiciones de las comunidades de origen también permanecen constantes, lo cual obliga a la permanente movilidad; por otro lado, para los polos de atracción o los sectores agrícolas, en este caso, la contratación de fuerza de trabajo procedente de estas

\footnotetext{
${ }^{10}$ Información obtenida a través de entrevistas a funcionarios del PTAT en Chetumal, Quintana Roo
} 
comunidades sigue siendo rentable para el desarrollo y crecimiento de las farmas. Es más, que es la rentabilidad que genera la contratación de la fuerza de trabajo de estas comunidades, debido a sus bajos costos, el principal insumo de la producción agrícola en Canadá; sin embargo, los campesinos y sus comunidades enfrentan adicional a la sobre explotación y discriminación que experimentan en Canadá, las dinámicas del capitalismo monopólico local azucarero.

\section{Condiciones laborales en Canadá}

La extensión de Canadá lo coloca como uno de los países más grandes del mundo, pero con una población reducida, pues cuenta con 9.92 millones de $\mathrm{km} 2$ y 35.2 millones de habitantes según las cifras registradas en el 2013, ocupa el lugar número 8 de los países más desarrollados a nivel mundial, el sector agroalimentario es de gran importancia para este país pues posee 43 millones de tierra arable, la disponibilidad de tierra óptima para el cultivo y el acervo de agua permiten aumentar la producción agrícola sin poner en riesgo sus recursos naturales (Olana Blasco, 2015).

Canadá produce más del $70 \%$ de su consumo interno, y es prácticamente autosuficiente en carne, lácteos, huevo, pan y cereales, posee aproximadamente 70,000,000 de hectáreas para el cultivo en provincias como Alberta, Columbia Británica, Isla Príncipe Eduardo, Manitoba, New Brunswick, Nueva Escocia, Ontario, Quebec y Saskatchewan, por lo que la agroindustria es una de las más importantes del país, produciendo principalmente frutas, verduras, hortalizas y forrajes, aunque también dedica parte de sus hectáreas a la producción de maíz y a la ganadería, además ha logrado una participación importante en la producción de tomate en invernadero (Gámez Gastélum, 2009).

La importación de mano de obra es vital para mantener los niveles de producción, el $62.44 \%$ de los asalariados que participan en el sector agrícola son temporales o estacionales, por lo que anualmente permite la entrada a hombres y mujeres jornaleros procedentes de países en desarrollo como México, Honduras, Guatemala y el Salvador, a través del programa de trabajadores agrícolas temporales.

En Canadá hay una asociación de productores, ellos nos reciben, nosotros solicitamos el permiso de trabajo, U\$1.200 dólares, cuesta el permiso y lo pagamos aquí. Las empresas son familiares, hay socios, son privados individuales, "el dueño que tengo" (sic) que es ahora mi patrón, empezó como encargado, y luego tiene la farma, nosotros semos como esclavos en tiempos modernos desde que salimos de aquí ya salimos con contrato y en el contrato dice cuánto vamos a trabajar, cuánto vamos a ganar, te dicen cuánto tiempo vas a trabajar diario. Puro engaño, porque si ya acabaste tus 8 horas y hay trabajo y no lo haces, para mañana está tu vuelo, sí, tenemos beneficios, pero no nos pagan lo que debe ser. No hay día de descanso, si dices voy a descansar y si descansas te sacan. El patrón es buena persona, 
y da trabajo, pero si haces algo que no le gusta, mañana te reemplaza, semos un número, mano de obra barata, esclavos, pero en tiempos modernos, no semos personas, semos como un tractor; uno que no va, no sirve, mañana te reemplazan por dos, no valemos nada, semos como un tractor. Desde que subimos al avión ya sabemos cuánto vamos a ganar y cuáles son las condiciones y las aceptamos todas, no hay de otra.

\section{La fuerza de trabajo es un insumo desechable}

Sólo les interesan los brazos, vitalidad y la capacidad de aguante, por eso no piden que hable idiomas porque no es necesario, ellos tienen capataces que hablan español y defienden con mucho celo al patrón. "Se comunican perfectamente con nosotros, y es el que mueve el circo". La figura del capataz para la producción es muy importante para el rendimiento haciendo cumplir las tareas con despotismo, a la vez que exacerba la individualización e impide los vínculos asociativos y la formación de un tejido social con demandas reivindicativas.

La peor farma en la que he estado, fue en Ontario, el problema era un capataz mexicano, son los peores, demasiado déspotas, pero son los que mueven el circo al patrón, cumplen sus órdenes maltratando y exigiendo mucho. Sólo un capataz chino puede superar en despotismo a un mexicano tal vez sí, los chinos son peores. Una vez en esa granja un compañero tenía más trabajo que yo y yo ya estaba por salir. Me puse a ayudarle para que sacara el trabajo y se vino el capataz y me dijo: aquí nadie se puede ayudar, cada uno a lo suyo y me pateó mi trabajo y me dijo levántalo, y yo agotado y al ver la humillación le dije: levántalo tú y hazle como quieras, y si no, le dije- que nos íbanos a arreglar a como se pudiera. Uno tiene miedo, pero el capataz también tiene miedo.

En efecto, de acuerdo a las experiencias de los trabajadores, para los dueños de las farmas, la fuerza de trabajo que compra a través de entidades como el PTAT es un insumo muy importante para la producción, pero que, en razón de la sobre oferta de mano de obra los trabajadores son prescindibles y reemplazables. Los trabajadores, por su parte, soportan jornadas extenuantes, racismo, discriminación o incumplimiento de contratos por la amenaza permanente de ser despedidos y quedar nuevamente en la fila de los desempleados en México.

*-El cuerpo de perdida necesita por lo menos un día, pero ellos ni siquiera respetan eso. Entre más le rindas a un patrón más te exige, nunca los tienes contentos.

*-Los trabajadores aprenden a controlar el rendimiento, el patrón está contento, pero es como una camioneta a la que le metes todo hasta adentro; tú tienes la culpa guey por qué le metes tanto y un trabajador que se deja explotar en demasía revienta a los demás.

*-Cuando tengo mucha obligación entro a las 4 de la mañana y salgo a las 12 de la noche, gano más, pero tengo más responsabilidad; uno lo hace por el dinero. 
*-Si sales mal con el patrón te comunicas y el cónsul te puede buscar un trabajo en otra farma, dan dos semanas de aprendizaje; montan un granero y lo acondicionan para que quepan hasta cuatro personas por cuarto.

\section{Migración circular, emprendimiento y transferencia de conocimiento}

Uno de los soportes más importantes que sirven de justificación de la migración circular señala que los trabajadores internacionales temporales son agentes de desarrollo económico en sus comunidades de origen; no solo por las remesas que se han convertido para México en la principal fuente de ingresos para el país por encima del petróleo y el turismo, sino porque, se argumenta que la permanencia en otros lugares permite a los migrantes vincularse con dinámicas innovadoras de producción, que en este caso estarían relacionadas con procesos adaptativos de cultivos, sistemas de riego, invernaderos o métodos de labranza; esquemas de rendimiento por hectáreas y de mercadeo, sin embargo, los campesinos ejidatarios la mayoría produce caña para abastecer al ingenio, y aunque han tratado de diversificar los productos, sembrando tomate, chiles, no es rentable; en razón de la cadena de intermediarios los trabajadores siembran en Rovirosa y no pueden ir a vender directamente; existe un entramado de relaciones complejas que van del sembrador al supermercado o al consumidor.

La figura más visible es el coyote que viene de México, Puebla, o Veracruz llega a comprar para llevarlo a México, lo compran según los campesinos que se dedican a eso, regalado, lo llevan en tráilers y de allá lo traen para abastecer a los supermercados a precios cinco o diez veces más caro, dependiendo de la temporada (el chile lo compran a 25 centavos el kilo y luego tú lo compras en 25 pesos en el super) el que sufre es uno.

El monocultivo y monopolio de las tierras es otro de los factores que impide el desarrollo económico de los trabajadores y por esta razón es un importante agente movilizador de los dinamismos migratorios.

El ingenio ha acaparado las tierras buenas y no deja entrar otras empresas como las tomateras que han ofrecido trabajo en la localidad, no permiten la variación o rotación de cultivos, solo monocultivo cañero. El ingenio no es dueño de la tierra, se hace de las tierras a través de la renta o, endeudando a los ejidatarios: el ingenio te obliga a adquirir un crédito para la producción de caña, para químicos, invertimos y nos endrogamos con el ingenio, si nos negamos a adquirir el crédito y a producir con nuestro dinero, sobre todo los que hemos juntado algo de capital trabajando en Canadá, entras en conflicto, no te compran el producto o te dejan para lo último, eso genera incertidumbre, no sabes si te vas a quedar con la caña o qué va a pasar.

La situación entre los ejidatarios y el ingenio es difícil, cada año firman un contrato que implica adquirir un crédito con altos intereses; dicho crédito está destinado para la compra de los fertilizantes y los plaguicidas, que le 
venden ellos mismos, "tú no puedes aplicarle el que tú creas conveniente" esas condiciones de la producción las pone el ingenio; ellos también dictan las condiciones, de compra y venta, de la caña de azúcar, si hay fluctuaciones en el precio el campesino debe asumir los riesgos y las perdidas.

Con el pretexto de aminorar los problemas que pudiera haber en la producción, "el ingenio te obliga a adquirir un seguro con una aseguradora, y casi nunca pagan si hay algún siniestro". De hecho, muchos de los que se fueron a Canadá fue porque fracasaron en la producción de caña por un siniestro y la aseguradora no cumplió, siempre se pegan de algo, que está en la letra chiquita del contrato con tal de no pagar. "Son una mafia", una dinámica corporativa entre el ingenio, el comisionado, las aseguradoras, los coyotes, los intermediarios. Los campesinos están prisioneros de esa cadena, la única manera de cortarla es saliendo, buscar trabajo afuera, por eso Canadá es un polo migratorio muy atractivo para los campesinos de Rovirosa.

La transferencia de conocimientos y la disminución del rezago a través de las remesas puede lograrse, según sus afirmaciones, si se impulsara la diversificación de productos agrícolas, aunado al encadenamiento entre producción, mercado, regulación de precios y consumo, conjuntamente con apoyos gubernamentales al campesino. El énfasis está colocado en la garantía de la compra de los productos.

Muchas veces los campesinos de Quintana Roo han producido chile, tomate, pero no lo pueden vender, tienen que pasar por coyotes que lo quieren comprar más barato que lo que le compran al campesino en Veracruz. Han intentado abrir mercado, pero los circuitos de compra-venta como lo han afirmado son una mafia, por esa razón muchas veces la gente ha tenido que tirar el producto porque no es rentable. Los mayas están en condiciones más difíciles. El gobierno, según sus afirmaciones, debería garantizar no solo la compra del producto al agricultor sino regular los precios; las preferencias en materia de apoyos a algunos cultivadores en detrimento de otros han ocasionado heridas en la comunidad.

Nosotros con tantos viajes que hemos hecho a Canadá ya tenemos una noción de cómo producir de cómo hacer algo, conseguir una procesadora con el conocimiento que ya tenemos si tuviéramos apoyo del gobierno emplearíamos a mucha gente y el Estado tendría autonomía alimentaria, podríamos hacer un invernadero, claro, necesitaríamos también asegurar que el gobierno nos compre, o tener asegurado un comprador, no es nada más sembrar, sino también quién nos compre. Aquí en la Ribera tiras una semilla y ya tienes asegurado el producto porque es buena tierra, es fértil, todo lo que se siembra se da, pero no beneficia al productor.

\section{Restitución del entorno, vidas de tiempo compartido}

El sostenimiento de los vínculos familiares, la restitución del entorno vital y familiar es otro de los indicadores del beneficio remarcados en la 
migración circular, sin embargo, los índices de divorcio son altos debido a las largas ausencias de los trabajadores, la gente siente que tiene trabajo seguro, trabajan 8 meses seguidos y descansan 4 pero al regreso a la comunidad el entorno familiar y comunitario ha sufrido sutiles transformaciones que liman los vínculos entre las personas.

El retorno es anhelado, sueñan permanentemente con los reencuentros familiares, los vecinos, fiestas y desquitar las cervezas que no se toman en Canadá por cara o porque una pasada de alcohol puede comprometer una jornada de trabajo y hasta la expulsión, sin embargo, debido a la intensidad de las jornadas el cuerpo se acostumbra y tiene sus horarios; en Canadá las casas de descanso están dentro de la farma de tal manera que la movilidad es mínima, al llegar a la comunidad estos patrones de conducta se han internalizado hasta biológicamente, de tal manera que no facilitan la sociabilidad del migrante con sus redes afectivas, en suma el migrante sufre transformaciones en el plano psicológico y la regulación orgánica.

*-El día descanso es para ir a hacer el envío de dinero, comprar tu despensa quizá tomar una cerveza y jala, regresar a descansar; uno se acostumbra a estar encerrado, cuando llegas a la comunidad los planes se esfuman rápido no quieres salir y solo piensas en reponer fuerzas, comer y no sales de tu casa; sólo vas a los centros comerciales a comprar cosas para tus hijos, para la familia y ya estuvo. con la familia, convives lo que puedes, escuchas los detalles de lo que ha pasado mientras estabas dejando el pellejo, he dejado a mis hijos pequeños, el último de 6 meses y cuando regresé ya estaba caminando, aunque he mantenido la familia estable, sé que el tiempo perdido no se recupera.

*-Las familias sufren, yo cuando fui mis hijos estaban grandes y no tuve tantos problemas, pero los de ahora no respetan al papá, es un extraño, no lo conocen, porque cuando se están encariñando con un hijo ya se tiene que ir.

*-Tú sabes que vas allá y sabes que te vas a matar, uno sabe, acá es más pesado, pero menos tiempo que en Canadá, pero te vas a matar. En Canadá ellos no te dan beneficio o reconocimiento adicional, pero nada, solo te sacan provecho y, al contrario, te sacan todo hasta dejarte escurrido. *-Los que sienten que se les acaban las fuerzas animan a los hijos a que se vayan, hay relevo generacional, darle de comer a la máquina.

*-Hay un técnico forestal, matemáticos, técnico en sistemas computacionales, pero prefieren ir allá; tienen profesión, pero si me pagaban 1500 pesos quincenales, así no se puede hacer ninguna vida; gracias a Dios; lo bueno de Canadá es que no hay diversión, todo es trabajo, y todo lo mandas, si gastas allá, ya el dinero no vale.

Reconocen los beneficios de estar en Canadá de forma regular en comparación con ir a Estados Unidos indocumentado.

Si llegas a Estados Unidos puedes moverte y buscar trabajo en diferentes cosas si no te gusta, pero prefieren ir a Canadá a esclavizarse, porque veo el progreso de lo que estoy haciendo, he mejorado mi casa, mantengo a mi esposa, hijos, ayudo a mis hermanos, si hay una necesidad de salud o para 
la educación de los chamacos, pero nosotros vivimos allá y venimos a la casa aquí a México a pasar vacaciones. Vivimos una vida de "tiempo compartido" mitad allá y mitad acá.

Al término de esta alocución preguntamos ¿Eso es vivir?, a lo que ellos respondieron, "pues es que vivimos para trabajar". Y toda la terraza de don Jorge González se llenó de alegres carcajadas.

\section{Conclusion}

En México la flexibilización laboral, la precarización del trabajo, los altos índices de pobreza y marginación son el saldo de la implementación del modelo neoliberal; en estos fenómenos encuentra anclaje la explicación a la intensidad de los flujos migratorios. La globalización, como hemos venido indicando, ha posibilitado el reclutamiento y aprovechamiento de la fuerza laboral de los llamados países en desarrollo para el crecimiento de las economías del norte. En este contexto es preciso indicar que, el nuevo orden social ha establecido nuevos mecanismos de apropiación de fuerza de trabajo y de gestión de las poblaciones a través modalidades de desplazamiento de los trabajadores mediante la figura de la migración circular. Una iniciativa que, por un lado, da solución a los problemas del campo y la crisis del empleo, en países como México y por el otro, sirve para solventar el déficit de mano de obra de los países desarrollados, en los hechos, los programas de empleo temporal son sólo un mecanismo para la reproducción y sostenibilidad de la fuerza de trabajo, para el crecimiento y desarrollo de la agroindustria en los países desarrollados.

Esta transacción compra y venta de mano de obra a través de la migración circular es mixta, se produce mediante instancias gubernamentales en el caso de México e instancias privadas en el caso de Canadá, no obstante, es el capital agrícola quien determina las reglas de operación, en tanto que el Estado nacional es un ente proveedor de un insumo de la cadena productiva reemplazable y desechable, ello en razón a la sobre oferta de mano de obra en el mercado internacional de fuerza de trabajo. Los derechos humanos de los trabajadores son moneda de cambio en esta transacción de compra y venta de fuerza de trabajo entre un país deficitario de mano de obra y un país con altos índices de desempleo.

La justificación de la migración circular en tres de sus rubros sustantivos, mantener los lazos familiares, ser agentes de desarrollo y ser agentes para la transferencia de conocimiento, es una falacia en el caso de los trabajadores de José Narciso Rovirosa; se ha reconocido a lo largo de este trabajo que debido al monopolio y monocultivo de la caña de azúcar del ingenio José Rafael de Pucté de capital privado, y las condiciones imperantes a través de contratos leoninos, que obliga a los trabajadores a contraer créditos 
para la producción con altos intereses, con el subsecuente traslado de todos los riesgos de la producción al campesino; por otro lado se advierte que la vocación decidida del capital agrícola local por el monocultivo de la caña de azúcar, impiden la diversificación de productos agrícolas e iniciativas de los migrantes con miras al emprendimiento para el desarrollo rural; la larga cadena de intermediarios para acceder al mercado, así como la falta de regularización de precios, y de apoyos gubernamentales para el campo son componentes que no permiten a los migrantes agrícolas temporales ser emprendedores ni transferir el conocimiento adquirido en las farmas canadienses. Son estas adversidades las que movilizan en los campesinos la idea del relevo generacional en las farmas, entregar brazos para el desarrollo agroindustrial canadiense y el abandono del campo en el país.

El carácter individualizador de la migración tiene impactos en las construcciones de sentido y los significados que las personas otorgan a la experiencia migratoria circular. Los migrantes asumen con una fuerte dosis de fatalidad su condición de brazos para el trabajo y la adquisición de bienes de consumo como la única posibilidad de reconocimiento y realización social y personal.

Finalmente, impedir el asentamiento y la integración del migrante en los países que demandan y compran fuerza de trabajo se ha presentado como un estímulo vinculante con el punto anterior con miras a mantener lazos familiares y comunitarios. Los trabajadores agrícolas temporales no solo son el soporte económico fundamental de sus familias, sino que han salido al relevo de las funciones del Estado en tareas sustantivas como, la educación y la salud; las remesas han servido para paliar el desempleo y la precariedad laboral en sus comunidades. En la comunidad hay un alto índice de divorcios y la ausencia del padre en las familias, resultado de las largas temporadas de ausencia, pone en entredicho una de las virtudes de la migración circular y genera en los trabajadores el imaginario de vivir una vida de tiempo compartido y apreciado tanto en México como en Canadá solo por su capacidad de rentabilidad.

\section{References:}

1. Achón Rodríguez, O. (2011). Contratación en origen e institución total. Estudio sobre el sistema de alojamiento de trabajadores agrícolas extranjeros en el Segriá (Lleida). http://diposit.ub.edu/dspace/handle/2445/35217

2. Bauer, M., \& Stewart, M. (2013). Cercano a la esclavitud. Programa de Trabajadores Huéspedes en los Estados Unidos. 52.

3. Bauman, Z. (2004). Vidas Desperdiciadas: La modernidad y sus parias. Paidós. 
https://www.academia.edu/39060021/ZYGMUNT_BAUMAN_VID AS_DESPERDICIADAS

4. Castellanos, D. R. L. (2014). Migración Circular de Trabajadoras de México a Canadá y Estados Unidos: Una Aproximación Antropológica Interseccional. 237.

5. CONSULMEX (2017). PTAT. https://consulmex.sre.gob.mx/toronto/index.php/es/ptat

6. Dávila, G. R. (2019). Globalización entre muros y fronteras: Escenario de la migración internacional. 10(19), 22.

7. Durand, J. (2006). Programa de Trabajadores Temporales: Evaluación y análisis del caso mexicano (Primera Edición). CONAPO. http://www.conapo.gob.mx/en/CONAPO/Programas_de_trabajadores _temporales_Evaluacion_y_analisis_del_caso_mexicano_2007

8. Fargues, P. (2008). Circular Migration: Is it relevant for the South and East of the Mediterranean? 18.

9. Gámez Gastélum, R. (2009). Evaluación del programa de trabajadores agrícolas temporales México-Canadá. Caso Sinaloa. https://www.eumed.net/cursecon/ecolat/mx/2009/rgg.htm

10. Garrido, F. (2004). GLOBALIZACIÓN Y MIGRACIÓN. 29.

11. Gordo, M. (2008). La contratación en origen de rumanos para actividades agrícolas de temporada en España. Cuadernos de Geografía de la Universitat de València, 0. https://doi.org/10.7203/CGUV..14363

12. Gualda, E. (2012). Migración circular en tiempos de crisis. Mujeres de Europa del Este y africanas en la agricultura de Huelva. Papers: revista de sociologia, 613-640.

13. INEGI, I. N. de E. y G. (2013). Catálogo Localidades. http://www.microrregiones.gob.mx/catloc/contenido.aspx?refnac $=23$ 0040267

14. INEGI, I. N. de E. y G. (2016). Anuario estadístico y geográfico de Quintana Roo 2016. 410.

15. INEGI, I. N. de E. y G. (2020). Datos estadísticos. Instituto Nacional de Estadística y Geografía. INEGI. https://www.inegi.org.mx/datos/

16. Jumilla, A. R. (2002). Efectos de la globalización en las migraciones internacionales. Papeles de población, 8(33), 9-45.

17. López, R., \& Serrano, C. (2020). Anuario de migraciones y remesas 2020 (BBVA Bancomer\&CONAPO). BBVA,CONAPO \& SEGOB. https://www.bbvaresearch.com/wpcontent/uploads/2020/10/Anuario_Migracion_y_Remesas_2020.pdf

18. MAPS (2020). Google Maps. Google Maps. https://www.google.com.mx/maps/place/Jos\%C3\%A9+N.+Rovirosa, +Q.R./@18.1078963,- 
$88.7320411,15.25 \mathrm{z} /$ data $=! 4 \mathrm{~m} 5 ! 3 \mathrm{~m} 4 ! 1 \mathrm{~s} 0 \mathrm{x} 8 \mathrm{f} 5 \mathrm{bfec} 490 \mathrm{a} 4 \mathrm{bcf9}: 0 \mathrm{xa} 9649 \mathrm{f}$ $94014 \mathrm{e} 834 \mathrm{c} ! 8 \mathrm{~m} 2 ! 3 \mathrm{~d} 18.108539 ! 4 \mathrm{~d}-88.7262662$

19. Olana Blasco, J. (2015). La política agrícola de Canadá: Precios, Riesgos y Conocimiento. 108.

20. Raghavan, C. (2004). Globalización y movimientos migratorios. 11.

21. Sassen, S. (2003). Contrageografías de la Globalización. Género y ciudadanía en los circuitos transfronterizos. Trafi cantes de Sueños. http://www.acuedi.org/ddata/9217.pdf

22. Semarnat, \& Conafor (2014). Estudio de línea base de gobernanza e identidad en Quintana Roo. 156.

23. Suárez, D. (2008). Causas y efectos de la migración internacional. Perspectivas. 161-180.

24. Subsecretaría de Empleo y Productividad Laboral, Coordinación General del Servicio Nacional de Empleo, \& Subcoordinación General del Servicio Nacional de Empleo. (2016). Lineamientos de operación. Programa de Trabajadores Agrícolas Temporales México-Canadá.

25. Vega, D. A. (2010). Análisis Para la Produccion de Etanol y su Potencial Consumo en la Región del Sur de Quintana Roo. 112.

26. Zapata Martelo, E., Suaréz San Roman, B., \& Flores Hernández, A. (2010). Se van muchos y regresan pocos: Economía política feminista, acercamiento a la migración (México: Instituto Nacional de Desarrollo Social: Grupo Interdisciplinario sobre Mujer, Trabajo y Pobreza : Colegio de Postgraduados, 2010). INDESOL, Colegio de Postgraduados, GIMTRAP.

27. Zapata-Barrero, R., Faúndez García, R., \& Sánchez-Montijano, E. (2012). Circular Temporary Labour Migration: Reassessing Established Public Policies. International Journal of Population Research, 2012, 1-13. https://doi.org/10.1155/2012/498158 